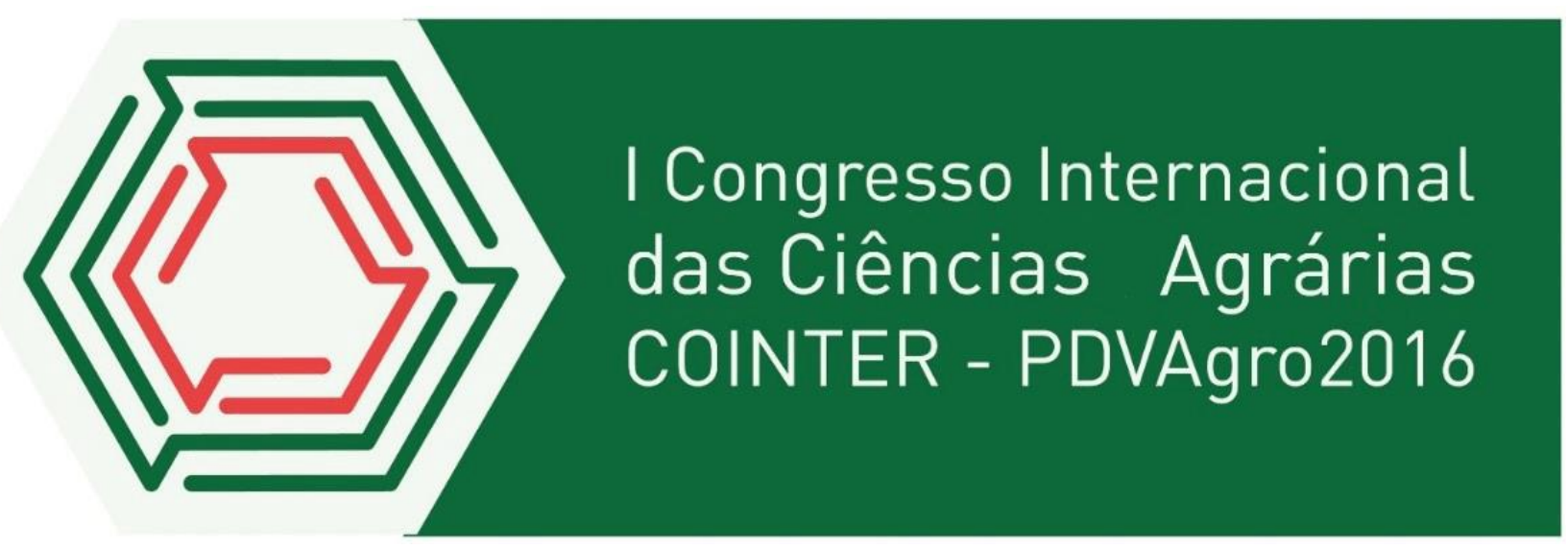

\title{
ATIVIDADES PRÁTICAS VOLTADAS PARA A EDUCAÇÃO AMBIENTAL COM DISCENTES DE UM COLÉGIO EM BANANEIRAS, PB
}

\author{
Apresentação: Pôster \\ João Henrique Constantino Sales Silva ${ }^{1}$; Raquel Tomaz Salustino²; Damiana Justino \\ Araújo $^{3}$; Vênia Camelo de Souza ${ }^{4}$; Gilvaneide Alves de Azeredo ${ }^{5}$
}

\section{Introdução}

Nas últimas décadas, as cidades tornaram-se cada vez mais verticalizadas, onde adultos e crianças passam a maior parte do tempo em ambientes pequenos, fechados e cimentados. O mesmo acontece nos ambientes de sala de aula, tornando o local pouco didático, onde segundo CHASSOT (2003), os conteúdos em sala são símbolos distantes da realidade do aluno, quando isso acontece o ensino deixa de ser transformador da realidade e passa a ficar aprisionado no interior das salas não tendo significado concreto em suas vidas.

Diante do exposto, este trabalho tem por objetivo relatar a experiência vivenciada junto aos discentes do $4^{\circ}$ e $5^{\circ}$ ano do Colégio Antônio Coutinho de Medeiros, situado no município de Bananeiras - PB, a respeito de uma atividade prática voltada para a educação ambiental, envolvendo a produção e distribuição de mudas de diferentes espécies florestais e, com isso, sensibilizar os discentes quanto à necessidade urgente de preservamos o meio ambiente. Este trabalho é parte do projeto de extensão Probex/2016 intitulado: “Interagindo com a Ecologia: produção de mudas de espécies nativas visando à conscientização ambiental”.

\footnotetext{
${ }^{1}$ Graduando em Bacharelado em Agroecologia, Universidade Federal da Paraíba, joaoagroecologia@outlook.com ${ }^{2}$ Licenciatura em Ciências Agrárias, Universidade Federal da Paraíba, raqueltomaz@live.com ${ }^{3}$ Licenciatura em Ciências Agrárias, Universidade Federal da Paraíba, damianaaraujo18@gmail.com

${ }^{4}$ Doutora, Universidade Federal da Paraíba, venia_camelo@hotmail.com

${ }^{5}$ Doutora, Universidade Federal da Paraíba, azeredogil@yahoo.com.br
} 


\section{Fundamentação Teórica}

A consciência a respeito da problemática ambiental cresceu significativamente nos últimos anos. Assim, questões como desmatamento, manejo sustentável e conservação de florestas passaram a ter grande destaque, inclusive na mídia internacional (NARDELLI, 2001). A importância da recuperação advém da necessidade de retenção do solo, contenção da erosão, manutenção da biodiversidade e da beleza cênica (FELFILI, 2001).

Segundo FERRO (2012), a recuperação de áreas degradadas é muito antiga, problemas como o assoreamento dos rios, inundações e deslizamentos causados pela degradação florestal não são recentes, no entanto, só recentemente esta adquiriu um caráter de uma área de conhecimento, os programas de recuperação deixam de ser mera aplicação de práticas agronômicas ou silviculturais para assumir a tarefa de reconstrução dos processos ecológicos. No Brasil, tem-se verificado nos últimos anos, uma grande preocupação com a preservação das florestas naturais, bem como com a recuperação de áreas degradadas e recomposição de matas ciliares destruídas ou perturbadas.

Portanto, o tema transversal "Meio Ambiente na Escola", configurado como Educação Ambiental, estimula-nos a adotar um olhar mais globalizante sobre questões complexas com as quais convivemos em nossa cidade, em nosso país e no mundo e, ainda, nos faz refletir sobre nosso comportamento diante do próximo e da natureza (NEHME e BERNARDES, 2011).

\section{Metodologia}

Em Junho/2015, este projeto foi desenvolvido no Colégio Antônio Coutinho de Medeiros, sendo feito o acompanhamento posterior das mudas produzidas pelos estudantes. Este ano, a vivência foi dividida em dois encontros realizados no mês de Setembro/2016. Ao chegarem à Universidade Federal da Paraíba - Campus III/Bananeiras, os estudantes foram conduzidos a conhecer o Setor de Agricultura e o ambiente ao redor, visando identificar algumas espécies arbóreas, sendo elas nativas e/ou exóticas. Neste momento, era explicado o conceito de espécies nativas e exóticas fazendo uso de estratégias trazidas a partir do conhecimento dos alunos, bem como de sua comunidade de origem. 
Em seguida, no gramado do pátio da universidade foram explicadas algumas etapas que são cruciais no processo de produção de mudas, através de uma linguagem de simples compreensão para um melhor entendimento dos discentes. Em seguida, com a ajuda da equipe de voluntários e das professoras presentes, os estudantes padronizaram os saquinhos (cortando com tesoura em um mesmo tamanho e fazendo furos na parte inferior dos sacos) reutilizados de feijão, arroz, açúcar e materiais semelhantes $(1 \mathrm{~kg})$, coletados no restaurante universitário. Posteriormente, os discentes foram levados até o Viveiro de Produção de Mudas do CCHSA, aonde preencheram os saquinhos com o substrato enriquecido em matéria orgânica. Antes da semeadura, os estudantes realizaram a escarificação mecânica, em lixa, para quebrar a dormência de algumas sementes florestais a exemplo da Saboneteira (Sapindus saponaria). Segundo SANTOS JÚNIOR e SILVA (2016), apesar de impedir a germinação, a presença da dormência não é necessariamente uma desvantagem, pois esta característica permite uma melhor distribuição da germinação ao longo de um intervalo de tempo, onde novas plantas podem se formar em períodos irregulares. No entanto, quando se trata de produção de mudas, a dormência precisa ser superada, visto que é um fenômeno que restringe a multiplicação destas espécies em viveiros.

\section{Resultados e Discussões}

Ao produzir mudas, a criança é estimulada em todos os sentidos. Ela aprecia a estrutura morfológica dos órgãos das plantas, percebe a diversidade de cores nas sementes e sente a textura do solo. Livre no ambiente, a criança está o tempo todo buscando e observando. Dessa forma, se a criança cresce em contato com a natureza, possivelmente ela será um defensor ambiental, por entender que ela também é parte da natureza.

Imagem 1: Escarificação de sementes com lixa e enchimento dos saquinhos reaproveitados. Fonte: Própria

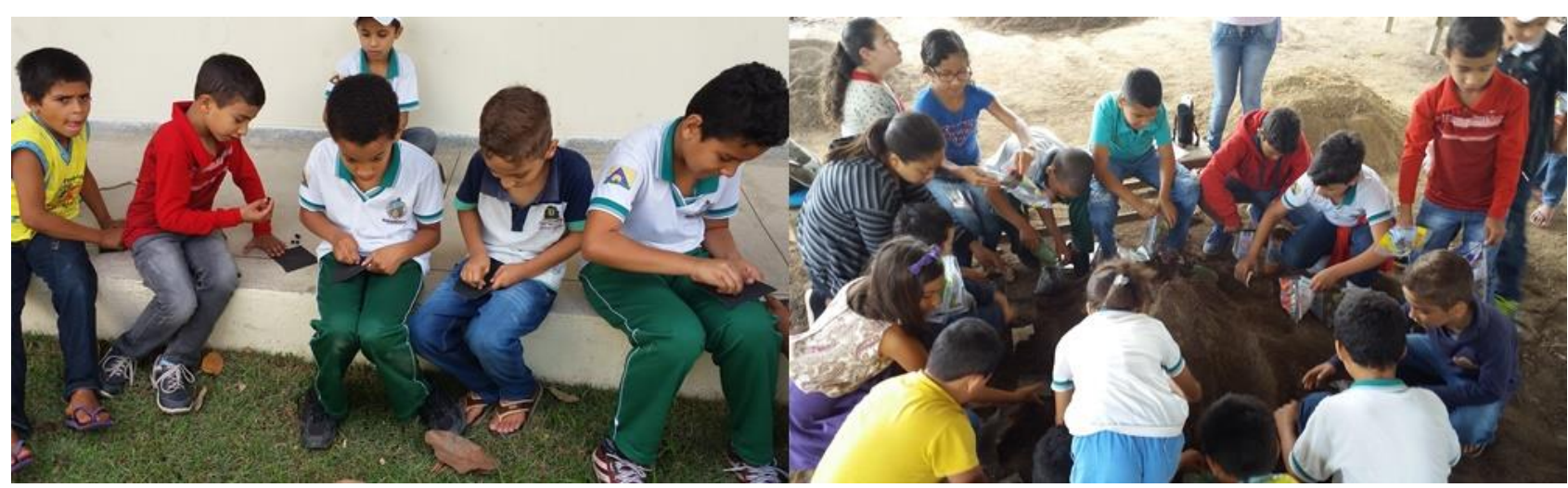


Foram produzidas aproximadamente 100 mudas, como ato simbólico, de quatro espécies florestais nativas, entre elas: o Chichá (Sterculia striata) e a Timbaúba (Enterolobium contortisiliquum). Ao final da prática cada estudante levou consigo uma muda nativa com idade e tamanho de ser plantada no quintal de casa, ou em qualquer outro lugar adequado para o plantio, conforme as orientações que receberam.

Imagem 2: Semeadura feita pelos estudantes e doação de mudas de espécies florestais nativas. Fonte: Própria

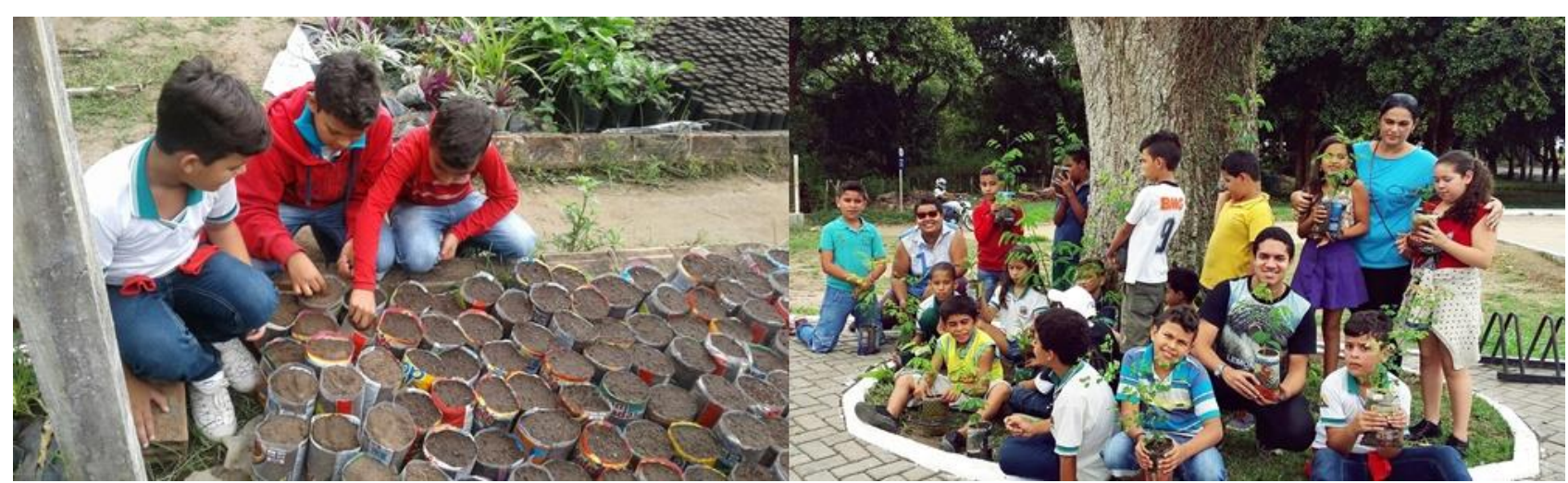

\section{Conclusões}

$\mathrm{O}$ interesse por parte dos estudantes em relação às atividades em campo aumentou significativamente, o que reflete de forma positiva na vida dos mesmos, aplicando seus conhecimentos no cotidiano. Alguns deles chegaram a relatar, inclusive, que as mudas doadas no ano anterior já passam de 1,5 m de altura aproximadamente. Essa vivência não só aproximou os discentes à natureza, como também os docentes responsáveis pela turma que acompanharam esses dias de campo.

\section{Referências}

CHASSOT, A. I. Alfabetização científica: questões e desafios para a educação. 3. ed. Ijuí: Ed. Unijuí, 2003. 436 p.

FELFILI, J.M.; SILVA JUNIOR, M.C. de. Biogeografia do bioma cerrado: estudo fitofisionômico da chapada do Espigão Mestre de do São Francisco. Brasília: UnB/ Departamento de Engenharia Florestal, 2001. Cap. 6, p. 35-36. 
FERRO, P. D.; SOUZA de, A. A.; CALDEIRA, D. R. M. Avaliação do Desenvolvimento de Espécies Arbóreas em Recuperação de Mata de Ripária. III Congresso de Gestão Ambiental. Goiânia/GO, Brasil, 2012.

NARDELLI, A. M. B. Sistemas de certificação e visão de sustentabilidade no setor florestal brasileiro. 2001. 121f. Tese (Doutorado em Ciência Florestal) - Universidade Federal de Viçosa, Viçosa, MG, 2001.

NEHME, V.G.; BERNARDES, M.B. Projetos e metodologias para a formação de sujeitos ecológicos. In: SEABRA, G. Educação ambiental no mundo globalizado. João Pessoa: Editora Universitária/UFPB, 2011, p.223-232.

VIEIRA, I. G.; FERNANDES, G. D. Métodos de quebra de dormência. Instituto de Pesquisas e Estudos Florestais - Piracicaba, São Paulo, Brasil, 1997.

SANTOS JÚNIOR, R. N.; SILVA da, A. G. Superação de dormência em sementes de Koelreuteria paniculata Laxm. Enciclopédia Biosfera, Centro Científico Conhecer - Goiânia, v.13 n.23; p. 2016 